\title{
Diagnóstico de los servicios de Radiología en medio de la pandemia
}

María Antonieta Londoño Arévalo Carolina Gómez Rodríguez²

\begin{abstract}
Editoras invitadas
'Radióloga, Pontificia Universidad Javeriana. Estudiante de Gerencia de la Calidad en Salud, Universidad El Bosque. ORCID ID: https://orcid.org/0000-0002-1441-3354

${ }^{2}$ Directora de Radiología e Imágenes diagnósticas, Hospital Universitario de San Ignacio. Instructora de Radiología e Imágenes diagnósticas, Pontificia Universidad Javeriana. Maestría en administración de empresas, Universidad de los
\end{abstract} Andes. Maestría en telesalud, Universidad de Antioquia

A propósito de la contingencia que se está viviendo mundialmente y de las recomendaciones emitidas por las diferentes sociedades científicas y grupos de expertos mundiales, es importante acercarnos a la realidad local (1).

Se resalta el gran esfuerzo de la Asociación Colombiana de Radiología al reunir un grupo de expertos nacionales en imágenes torácicas que permitieron emitir el documento "Recomendaciones de la ACR para el transporte, realización de estudios, aislamiento de equipos, medidas de seguridad del personal e interpretación de imágenes diagnósticas durante la pandemia en concordancia con el consenso de la Asociación Colombiana de Infectología para la atención, diagnóstico y manejo de infección por SARS-CoV-2/COVID-19" (2,3). Esto permitió informar rápidamente a los servicios de radiología del país sobre cómo estar preparados para la atención durante la pandemia.

Para evaluar la realidad local y el contexto en el que nos encontramos, se considera importante conocer los datos de población y la disponibilidad de servicios de radiología. Según el Censo de 2018, realizado por el Departamento Administrativo Nacional de Estadística (DANE), Colombia contaba para ese entonces con una población estimada de 48.258.494 personas, de los cuales $15,8 \%$ residían en área rural dispersa, y 7,1\%, en centros poblados; los restantes, en áreas urbanas. Según las estimaciones de la misma entidad, para febrero de 2020, se cruzaría el umbral de los 50.000.000 de colombianos (4).

Adicionalmente, debe considerarse la disponibilidad de servicios de ayudas diagnósticas que puedan orientar al personal de salud en la toma de decisiones. Para la fecha de corte 29 de febrero de 2020, con última fecha de actualización del 18 de marzo de 2020, el subgrupo Radiología e Imágenes Diagnosticas (5), tiene 1.965 prestadores de salud inscritos, sin discriminar cuáles ayudas diagnósticas están disponibles en cada una de las instituciones prestadoras de salud (IPS). En especial, no se describen los prestadores que proveen el servicio de tomografía axial computarizada (TAC) y, por lo tanto, estos no pueden ser mapeados en el visor geográfico del Sistema Integrado de Información de la Protección Social (SISPRO) (6).

Para lograr una aproximación al conocimiento de los prestadores de ayudas diagnósticas con este tipo de servicio, se realizó una consulta en el CUBO (herramienta de SISPRO que permite generar estadísticas) y en los registros individuales de prestación de servicios de salud (RIPS) de los procedimientos relacionados con codificación única de procedimientos (CUPS) que incluyeran tomografías (exclu- yendo los estudios odontológicos y oftalmológicos). De esta manera se obtuvieron los prestadores que reportaron estas atenciones durante 2019.

Dicha consulta hace evidente cómo las regiones más alejadas del país tienen escasez de recursos; es así como en departamentos como Guainía no se reportó ninguna tomografía durante 2019, pues cuenta únicamente con radiografías convencionales en su capital, Puerto Inírida. En Vichada y Vaupés se encontró un solo prestador con disponibilidad de tomografías. En el Archipiélago de San Andrés y Providencia solo se reportaron dos instituciones prestadoras; en Amazonas y Guaviare, tres, y en Chocó, seis (tabla 1).

Tabla 1. Número de prestaciones de tomografía durante 2019 (Basado en CUBO/SISPRO)

\begin{tabular}{|c|c|c|c|}
\hline Zona & Departamento & Número & Subtotal \\
\hline \multirow{6}{*}{ Amazonía } & Amazonas & 3 & \multirow{6}{*}{28} \\
\hline & Vaupés & 1 & \\
\hline & Guainía & 0 & \\
\hline & Guaviare & 3 & \\
\hline & Caquetá & 8 & \\
\hline & Putumayo & 13 & \\
\hline \multirow{4}{*}{ Orinoquía } & Meta & 33 & \multirow{4}{*}{67} \\
\hline & Vichada & 1 & \\
\hline & Arauca & 10 & \\
\hline & Casanare & 23 & \\
\hline \multirow{4}{*}{ Pacífico } & Chocó & 6 & \multirow{4}{*}{215} \\
\hline & Valle del cauca & 140 & \\
\hline & Cauca & 27 & \\
\hline & Nariño & 42 & \\
\hline
\end{tabular}

Fuente: Elaboración propia.

Estos resultados se correlacionan con el estimativo de sedes que ofrecen servicio de TAC en Colombia por departamentos 2013 2014, figura 11 del documento “Atlas de variaciones geográficas de salud en Colombia" (7). 
Es llamativo que no existe un censo del talento humano en cada una de las regiones del país, por lo que se desconoce con certeza el número de radiólogos disponibles en cada departamento, pero se estima que, al igual que en la cantidad de servicios habilitados, existe inequidad entre las regiones.

En situaciones como esta se visualizan las desigualdades existentes en las diferentes regiones del país en muchos aspectos, incluido el acceso a los servicios de salud, y se pone en jaque el sistema de salud colombiano. Se hace evidente el déficit de talento humano, especialmente en algunas zonas alejadas del país, y que la capacidad instalada tanto tecnológica como de camas, más aún las de unidades de cuidados intensivos es insuficiente para atender a nuestra población. Es así como en ciudades capitales de departamentos, como Leticia, donde se han reportado numerosos casos positivos de COVID-19, no se dispone de unidades de cuidados intensivos que permitan atender los pacientes complicados por esta pandemia o por otras patologías.

El reto para el Gobierno y para las entidades de salud aumenta si se tiene en cuenta las megatendencias demográficas y poblacionales: la demanda de los servicios de salud se ha visto influenciada por diversos factores: migraciones, el crecimiento de las ciudades y los cambios en la expectativa de vida, entre otros. Algunos estudios indican que en las próximas décadas América Latina experimentará una reducción en su población menor de 15 años y un aumento en la de mayores de 64 años (8), lo cual cambiará los perfiles de riesgo en salud y, por lo tanto, la dinámica de los programas de salud definidos por el Gobierno y el Ministerio de Salud.

Por otro lado, las ciudades intermedias tenderán a crecer en porcentajes mucho más elevados que las ciudades principales, debido, entre otras causas, a la migración de ciudadanos extranjeros. Estas tendencias demandan planificar y organizar los sistemas de salud teniendo en cuenta estos cambios en la población.

Cabe anotar que, de acuerdo con cifras publicadas por Migración Colombia con corte al 29 de febrero de 2020, en Colombia estarían radicados más de 1.825.000 venezolanos (9), lo que genera un incremento en la demanda de los servicios de salud.

Estos cambios poblacionales exigen, para contrarrestar el impacto en el sistema de salud, una adecuada administración de los recursos disponibles, casi siempre escasos, en los estrechos presupuestos estatales de salud, para el desarrollo de programas que atiendan de manera conveniente las necesidades de toda la población. De este modo, en la medida de lo posible y en cuanto a la salud se refiere, se debe lograr que ningún ciudadano sea víctima de la inequidad y que pueda hacer uso de los servicios de salud con seguridad, eficacia y efectividad, como lo contempla la ley estatutaria 1751 de 2015.

El modelo actual del Sistema General de Seguridad Social en Colombia está basado en el equilibrio que debe existir en los volúmenes de atención prestados por las instituciones con diferentes niveles de complejidad asistencial. Se busca que la mayoría de los eventos sean atendidos por entidades de baja complejidad y que un mínimo porcentaje de estos sean remitidos a los niveles de complejidad superior; dicho equilibrio no se ha logrado, ya que la mayor parte de las atenciones de salud son realizadas por instituciones de mediana y alta complejidad. Esto se debe a la falta de capacidad resolutiva, al personal poco calificado y a la infraestructura deficiente que tie- nen las instituciones prestadoras de salud de baja complejidad. Se requiere un nuevo enfoque del modelo, que dinamice y fortalezca la capacidad de las instituciones de baja complejidad y libere a las instituciones de los demás niveles de atención en salud del colapso en que se encuentran (10).

Por todo lo anterior, es necesario conocer en detalle los recursos de infraestructura, técnicos y humanos en salud en las diferentes regiones del país, hacer los ajustes que se requieran de acuerdo con la población, la oferta y la demanda y no apoyarse únicamente en estimativos o aproximaciones para continuar trabajando por el oportuno diagnóstico de las diferentes patologías de los habitantes de nuestro país.

En lo que corresponde al área de la radiología e imágenes diagnósticas en la atención en salud durante esta contingencia, se abre aun más la puerta al uso de recursos como la telemedicina y el telediagnóstico para atender la población más vulnerable y orientar al personal de salud de lugares remotos de nuestra geografía. Sin embargo, para esto se requiere atraer recursos e invertir en tecnología instalada en estas regiones alejadas.

\section{Referencias}

1. Rubin GD, Haramati LB, Kanne JP, Schluger NW, Yim J-J, Anderson DJ, et al. The role of chest imaging in patient management during the COVID-19 pandemic: A multinational consensus statement from the Fleischner Society. Radiology [internet]. 2020;201365. Disponible en: http://www.ncbi.nlm.nih.gov/pubmed/32255413

2. Asociación Colombiana de Radiología. Recomendaciones de la Asociación Colombiana de Radiología para el transporte, realización de estudios, aislamiento de equipos, medidas de seguridad para el personal e interpretación de imágenes diagnósticas durante la pandemia por el COVID-19 [internet]. 23 de marzo de 2020. Disponible en: https://www.acronline.org/COVID-19/ArtMID/4054/ArticleID/7573/ Recomendaciones-de-la-ACR-para-el-transporte-realizaci243n-de-estudios-aislamiento-de-equipos-medidas-de-seguridad-del-personal-e-interpretaci243n-de-im225genesdiagn243sticas-durante-la-pandemia

3. Infectología Asociación Colombiana. Consenso colombiano de atención, diagnóstico y manejo de infección por SARS-COV-2/COVID-19 en establecimientos de atención de la salud. Recomendaciones basadas en el consenso de expertos e informadas en la evidencia. Infectio. 2020;24:1-112.

4. Departamento Administrativo Nacional de Estadística (DANE). ¿Cuántos somos? [internet]. S. f. [citado: 26 de abril de 2020]. Disponible en: https://www.dane.gov. co/index.php/estadisticas-por-tema/demografia-y-poblacion /censo-nacional-depoblacion-y-vivenda-2018/cuantos-somos

5. Ministerio de Salud. Reporte Especial de Prestadores de Servicios de Salud (REPS). [internet]. 18 de marzo de 2020. Disponible en: https://prestadores.minsalud.gov.co/ habilitacion/

6. Ministerio de Salud. Sistema Integral de Información de la Protección Social (SISPRO) [internet]. 2013 [citado: 27 de abril de 2020]. Disponible en: https://sig.sispro.gov.co/ sigmsp/index.html

7. Alfonso EA, Arcila A, Latorre ML. Atlas de variaciones geográficas en salud de Colombia. Informe de investigación [internet]. 2017 [citado: 26 de abril de 2020]. Disponible en: http://documentos.bancomundial.org/curated/es/22004153148476518 9/Atlas-de-variaciones-geogr $\% \mathrm{C} 3 \%$ A 1 ficas-en-salud-de-Colombia

8. Flórez CE, Villar L, Puerta N, Berrocal LF. El proceso de envejecimiento de la población en Colombia: 1985-2050 Bogotá: Editorial Fundación Saldarriaga Concha; 2015.

9. Ministerio de Relaciones Exteriores. Más de 1.825.000 venezolanos estarían radicados en Colombia [internet]. 3 de abril de 2020 [citado: 12 de mayo de 2020]. Disponible en: https://www.migracioncolombia.gov.co/noticias/265-abril-2020/mas-de-1-millon825-mil-venezolanos-estarian-radicados-en-colombia

10. Ministerio de Tecnologías de la Información y la Comunicación (MinTIC). Agenda estratégica de innovación. Nodo salud [internet]. Marzo de 2014 [citado: 12 de mayo de 2020]. Disponible en: https://www.mintic.gov.co/portal/604/articles-6118 recurso_2.pdf 